\begin{tabular}{|l|}
\hline Access this article online \\
\hline Quick Response Code: \\
\hline
\end{tabular}

Department of Microbiology, Sri Ramachandra Institute of Higher Education and Research, Chennai, Tamil Nadu, India

Address for correspondence:

Dr. Thayanidhi

Premamalini,

Department of

Microbiology,

Ramachandra Institute of Higher Education and Research,

Chennai - 600116

Tamil Nadu, India. E-mail: drtpremamalini@ gmail.com

Submission: 20-03-2018 Accepted: 11-09-2018

\title{
Evaluation of 3-(4,5-dimethylthiazol- 2-yl)-2,5-diphenyl tetrazolium bromide method for assessing biofilm formation in vitro by Trichosporon spp.
}

\author{
Thayanidhi Premamalini, Subramanian Anitha, Kanniappan Mohanapriya, \\ Anupma Jyoti Kindo
}

\begin{abstract}
:
BACKGROUND: Invasive infections due to Trichosporon spp. have increased recently and are frequently associated with indwelling medical devices. Such infections which are associated with biofilm formation do not respond to the routinely used antifungal agents and are often persistent, associated with high mortality rate. Various methods have been described by researchers to evaluate and quantify the biofilm formation.
\end{abstract}

AIM: This study was conducted to compare two methods of biofilm production by Trichosporon sp, i.e., test tube method with crystal violet (CV) staining and 3-(4,5-dimethylthiazol-2-yl)-2,5-diphenyl tetrazolium bromide (MTT) assay.

MATERIALS AND METHODS: Seventy-two clinical isolates of Trichosporon spp. collected from various sources were considered for the study. The identity of all the isolates was genotypically confirmed by Trichosporon-specific polymerase chain reaction (PCR). The isolates were further speciated phenotypically using biochemical profile and growth characteristics which identified the isolates as Trichosporon asahii (64/72), Trichosporon asteroides (5/72), Trichosporon cutaneum (2/72), and Trichosporon mucoides (1/72). Biofilm production was then evaluated and compared by test tube-CV method and MTT assay.

RESULTS: All the Trichosporon isolates produced biofilm by MTT assay, whereas only 42 (53.6\%) of the isolates were detected to be biofilm producers by CV method. Furthermore, MTT assay could differentiate better between weak and moderate biofilm producers as compared to $\mathrm{CV}$ method.

CONCLUSION: Hence, MTT assay is a reliable method for quantification of biofilm produced by Trichosporon spp. using 96-well microtiter plate.

Key words:

3-(4,5-dimethylthiazol-2-yl)-2,5-diphenyl tetrazolium bromide assay, biofilm, crystal violet method, Trichosporon $\mathrm{sp}$

\section{Introduction}

Biofil iofilms are microbially derived sessile community of cells that are irreversibly attached either to the surface or each other. ${ }^{[1]}$ They can also form in other environments such as liquid-air interfaces. The properties

This is an open access journal, and articles are distributed under the terms of the Creative Commons Attribution-NonCommercial-ShareAlike 4.0 License, which allows others to remix, tweak, and build upon the work non-commercially, as long as appropriate credit is given and the new creations are licensed under the identical terms.

For reprints contact: reprints@medknow.com of this group of adherent cells are distinct from those of free-floating (planktonic) cells. ${ }^{2]}$ An important characteristic of biofilms, compared to the planktonic cells, is the greater resistance of these cells to chemical and physical insults. ${ }^{[3]}$

The genus Trichosporon is an anamorphic basidiomycetous yeast, with a distinct

How to cite this article: Premamalini $T$, Anitha S, Mohanapriya K, Kindo AJ. Evaluation of 3-(4,5-dimethylthiazol-2-yl)-2,5-diphenyl tetrazolium bromide method for assessing biofilm formation in vitro by Trichosporon spp.. J Lab Physicians 2018;10:380-6. 
morphological characteristic feature of budding yeast cells and true mycelium which disarticulates to form arthroconidia. Disseminated life-threatening infections due to Trichosporon spp. is common in patients with underlying hematological malignancies, extensive burns, solid tumors and transplant recipients, which accounts for $10 \%$ of all confirmed cases of disseminated fungal infections. Such infections due to invasive Trichosporon spp. are usually associated with central venous catheters, vesical catheters, and peritoneal catheter-related devices. ${ }^{[4]}$ Prosthetic devices could act as substrates for adhesion and promote the growth of biofilms. ${ }^{[5]}$ The ability of the Trichosporon spp. to adhere to and form biofilms on implanted devices can account for the progress of invasive trichosporonosis. The formation and expression of biofilms by Trichosporon spp. are frequently associated with increased antifungal resistance due to upregulated drug efflux and other factors ${ }^{[6]}$ This can promote the escape from host immune responses and antifungal drugs ${ }^{[4]}$ At times regardless of the use of antifungal drugs to treat trichosporonosis, the infection is often persistently associated with high mortality. Since these biofilms are largely resistant to the current antifungal agents, high antifungal doses together with the removal of the colonized medical device are generally required to treat the infection. However, this may be dangerous or create complications in severely ill patients. ${ }^{[7]}$

Hence, this study was undertaken to assess the formation of biofilm in-vitro by Trichosporon spp isolated from clinical specimens. The purpose of this study was 2 -fold. The first objective was to evaluate biofilm formation by MTT assay. The second objective was to compare the MTT assay done in microtiter plate with the standard $\mathrm{CV}$ method performed in test tube.

\section{Materials and Methods}

Seventy-two strains of Trichosporon species isolated from clinical samples were used for the study.

Type of study: Hospital-based descriptive study.

Period of study: January 2011 to July 2016.

Place of study: Sri Ramachandra Medical College and RI, Chennai, Tamil Nadu, India.

\section{Collection of isolates}

Yeast-like colonies from clinical samples were initially observed for microscopic characteristics by Gram staining, Dalmau technique, and urease production. The isolates which showed the budding yeast cells, hyphae and arthroconidia by microscopy and were urease positive, were provisionally identified as Trichosporon species. These isolates were preserved at $-20^{\circ} \mathrm{C}$ on skimmed milk medium until use. ${ }^{[8]}$ Majority of our isolates were from urine, i.e., 43 (59.7\%), $12(16.7 \%)$ isolates were from blood, $7(9.7 \%)$ Trichosporon isolates grew from samples collected by percutaneous nephrostomy. The other isolates recovered from samples sources such as respiratory, pus and peritoneal dialysis fluid and their distribution is shown in Figure 1.

Control strains

For phenotypic characterization and Trichosporon-specific polymerase chain reaction

Trichosporon asahii MTCC 6179, Trichosporon asteroides MTCC 7632, Trichosporon cutaneum var. cutaneum MTCC 1963, Trichosporon jirovecii MTCC 9036, Candida albicans ATCC 90028, Candida krusei ATCC 6258.

\section{For biofilm production}

T. asahii MTCC 6179, T. asteroides MTCC 7632, T. cutaneum var. cutaneum MTCC 1963 and T. jirovecii MTCC 9036, Candida krusei ATCC 6258, and Candida tropicalis ATCC 750 .

\section{Trichosporon specific polymerase chain reaction DNA extraction}

Genomic DNA from clinical isolates, reference strains of Trichosporon species and reference strains of Candida species were isolated by in-house method..$^{[9]}$ Briefly, Briefly, $400 \mu \mathrm{l}$ of lysis buffer (10mM TRIS, pH - 8), $1 \mathrm{mM}$ ethylene diamine tetra acetic acid EDTA ( $\mathrm{pH}-8)$, $3 \%$ Sodium dodecyl sulfate (SDS) and $100 \mathrm{mM} \mathrm{NaCl}$ was taken in a 1.5-ml centrifuge tube. A loop full of Trichosporon culture was suspended in the lysis buffer and heated at $100^{\circ} \mathrm{C}$ in water bath for $1 \mathrm{~min}$. An equal volume of Phenol: Chloroform was added to this suspension and mixed well. It was then centrifuged at $10,000 \mathrm{rpm}$ for $10 \mathrm{~min}$. The aqueous layer was transferred to a fresh centrifuge tube, and the step was repeated again by adding chloroform to the supernatant. The DNA was precipitated with cold isopropyl alcohol, centrifuged and washed with $70 \%$ ethanol and dried. The pellet was later re-suspended in $30 \mu \mathrm{l}$ of Tris-EDTA buffer and stored at $20^{\circ} \mathrm{C}$ until use.

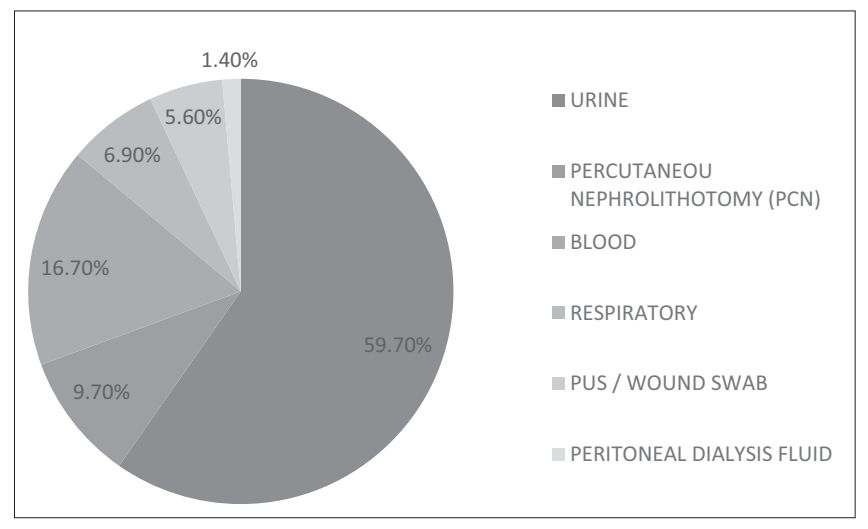

Figure 1: Sample source distribution of Trichosporon spp. 
Trichosporon-specific polymerase chain reaction Trichosporon genus-specific primers (TRF-5'AGAGCCTACCATGGTATCA 3' TRR5'TAAGACCCAATAGAGCCCTA 3') would precisely amplify only Trichosporon species, by aligning with the small subunit (SSU) of ribosomal DNA (rDNA) sequences, since this region is not conserved in other medically important yeasts. ${ }^{[10]}$ The polymerase chain reaction (PCR) master mix was prepared containing $25 \mu \mathrm{l}$ of PCR mix (Takara, Japan), $1 \mu$ of forward (TRF) and reverse primer (TRR) (GeNei, Bengaluru), $1 \mu \mathrm{l}$ of template DNA, and the volume made up to $50 \mu \mathrm{l}$ with sterile nuclease-free water. The reaction mixtures were amplified in a thermal cycler (Veriti 96 well, Applied Biosystems, USA), with the following program: $95^{\circ} \mathrm{C}$ for $7 \mathrm{~min}$, followed by 30 cycles consisting of $95^{\circ} \mathrm{C}$ for $30 \mathrm{~s}, 54^{\circ} \mathrm{C}$ for $30 \mathrm{~s}$, and $72^{\circ} \mathrm{C}$ for $30 \mathrm{~s}$, with a final extension period at $72^{\circ} \mathrm{C}$ for $10 \mathrm{~min} \cdot{ }^{[10]}$ After thermal cycling, $10 \mu \mathrm{l}$ of the amplified product was run on a $1.5 \%(\mathrm{wt} / \mathrm{vol})$ agarose gel, stained with ethidium bromide, and visualized with ultraviolet light.

\section{Species level phenotypic identification}

Microscopic characteristics of the isolates were studied using Dalmau technique on cornmeal agar with $1 \%$ tween 80 . The plates were incubated in a moist chamber at $25^{\circ} \mathrm{C}$ for $3-5$ days and observed under high power magnification for morphological features such as hyphae, budding yeast cells, arthroconidia, appressoria, and sarcinae. Biochemical characterization was done as described by De Hoogs et al., 2000. [11] The isolates were initially tested for fermentation and assimilation of basic sugars such as glucose, maltose, sucrose, lactose, galactose, and trehalose. Later, they were identified till species level, by physiological tests such as fermentation and assimilation of and growth on carbon sources, growth at various temperatures and $0.1 \%$ cycloheximide. ${ }^{[11]}$

Test for biofilm formation

Biofilm formation - Test tube method by crystal violet staining

Trichosporon isolates were tested for biofilm production by a modification of the standard method, using test tube and CV staining. ${ }^{[12]}$ Two milliliters Sabouraud dextrose broth in $12 \mathrm{~mm} \times 75 \mathrm{~mm}$ borosilicate test tubes were inoculated with a loopful of microorganisms from overnight culture plates and incubated for $48 \mathrm{~h}$ at $37^{\circ} \mathrm{C}$, after which the contents were decanted and washed with phosphate buffered saline (PBS) (pH 7.3) and left to dry at room temperature. Then, the tubes were stained with $4 \%$ solution of CV. Each tube was then gently rotated to ensure uniform staining, and then the contents were gently decanted. The tubes were placed upside down to drain and then observed for biofilm formation. ${ }^{[12]}$ All the isolates were tested in triplicates for confirmation of the findings. The formation of a visible film which lined the wall and bottom of the tubes is considered as positive. Ring formation at the liquid interface was not regarded as indicative of biofilm formation. The scoring was done by visual observation (absent -0 ; weak -1 ; moderate -2 ; and strong -3$) \cdot{ }^{[13]}$

Biofilm production - 3-(4,5-dimethylthiazol-2-yl)2,5-diphenyl tetrazolium bromide assay

MTT assay was done in a 96-well microtiter plate for the development of fungal biofilm. This assay includes the formation of multiple equivalent fungal biofilms on the bottom of wells of microtiter plates, combined with a colorimetric method that measures the metabolic activities of cells within the biofilm based on the reduction of the dye MTT.

\section{Biofilm formation}

To evaluate biofilm formation of Trichosporon spp. isolates in a 96-well microtiter plate, we adopted the protocol of Jin et al. and Di Bonaventura et al. with modifications. ${ }^{[5,14]}$ Clinical isolates of Trichosporon spp. and control strains were grown in yeast peptone dextrose broth at $35^{\circ} \mathrm{C}$ for $48 \mathrm{~h}$. They were subcultured in RPMI 1640 medium adjusted to $\mathrm{pH} 7.0$ with $0.165 \mathrm{M}$ MOPS (3-(N-morpholino) propanesulfonic acid) overnight under agitation at $37^{\circ} \mathrm{C}$. The cells were collected by centrifugation and washed twice with sterile PBS. They were re-suspended in RPMI 1640 (pH 7.0-MOPS), and the inoculum is adjusted to 0.5 Mcfarland turbidity standard which corresponds to $10^{5}$ cells $/ \mathrm{ml}$. Cell suspension of $100 \mu \mathrm{l}$ was added to 96-well flat-bottomed polystyrene plates. Eight wells were inoculated for single isolate. The plates were incubated at $37^{\circ} \mathrm{C}$ for $90 \mathrm{~min}$ (adhesion time). After incubation, the wells were washed twice with $150 \mu \mathrm{l}$ of PBS to remove the nonadherent cells. Finally, $150 \mu \mathrm{l}$ of RPMI 1640 (pH 7.0-MOPS) was added to each well. The plate was incubated at $37^{\circ} \mathrm{C}$ for $48 \mathrm{~h}$ (biofilm formation). Culture media were changed every $24 \mathrm{~h}$.

Biofilm quantification-3-(4,5-dimethylthiazol-2-yl)2,5-diphenyl tetrazolium bromide assay

Sessile cells were quantified using MTT assay as per Traba and Liang and Tsang et al. with modifications. ${ }^{[15,16]}$ For the assay, MTT is diluted 1:5 from the stock solution, i.e., $1 \mu \mathrm{g} / \mathrm{mL}$ working solution of MTT was prepared by diluting $5 \mu \mathrm{g} / \mathrm{mL}$ stock solution. To quantify the adhered living cells, $50 \mu \mathrm{L}$ of working solution of MTT was added to each well and incubated at $37^{\circ} \mathrm{C}$ for $4 \mathrm{~h}$. After incubation, MTT solution was aspirated and $100 \mu \mathrm{l}$ of dimethyl sulfoxide was added to each well to solubilize the insoluble end product formazan. The change in color in the MTT reduction assay, which represents the direct association of the metabolic activity of cells within the biofilm, was then measured spectrophotometrically in a microtiter plate reader. The absorbance was measured by setting the detection and 
reference wavelengths at $450 / 620 \mathrm{~nm}$ (read/reference), respectively. Each experiment was performed in triplicate, and biofilm quantifications were expressed as means of 24 readings (wells) per isolate \pm standard deviation (SD).

For easy interpretation, the isolates were categorized based on OD values if OD $\angle \mathrm{ODc}$ (cut off value) - No biofilm producer; $>$ ODc to $<2$ ODc - Weak biofilm producer; $>2 \mathrm{ODc}$ to $<4$ ODc - Moderate biofilm producer; and $>4$ ODc - Strong biofilm producer. ${ }^{[17]}$

\section{Statistical analysis}

All statistical analysis was performed using Statistical Package for Social Science (SPSS Inc, version 17, Chicago) for Microsoft Windows. Descriptive statistics were presented as numbers and percentages; the data were expressed as Mean and SD A Chi-squared test was used for comparison between two attributes. A two-sided $P<0.05$ was considered statistically significant.

\section{Results}

All the 72 clinical isolates considered for our study and the four reference strains exhibited morphological and microscopic characteristics compatible with Trichosporon genus. PCR was performed with Trichosporon genus-specific primers to double check for accurate identification of the genus. This pair of primer is Trichosporon specific and amplifies part of the nucleotide sequences of the rDNA SSU (18S). DNA bands of approximately $170 \mathrm{bp}$ were obtained for all the isolates tested and for Trichosporon reference strains [Figure 2]. In addition, there was no amplification of DNA isolated from Candida spp. (negative control). Therefore, all our strains were confirmed to belong to the genus Trichosporon.

The isolates were further speciated based on phenotypic characteristics. Fermentation was absent in all the isolates. Different biochemical and growth profiles of Trichosporon spp. are shown in Table 1. Hence, the isolates were identified phenotypically as T. asahii (64/72), T. asteroides (5/72), T. cutaneum (2/72), and Trichosporon mucoides $(1 / 72)$.

\section{Biofilm production}

Out of the 72 Trichosporon isolates studied, only 42 (58.3\%) of them produced biofilm by test tube $(\mathrm{CV})$ method and all the isolates produced biofilm by MTT assay.

\section{Biofilm quantification by crystal violet method}

Of the 42 biofilm producers detected by CV method, $5(6.9 \%)$ were weak biofilm producers, $17(23.6 \%)$ were moderate biofilm producers, and $20(27.8 \%)$ were strong biofilm producers.

B i of i l m quan $t$ if ic a tion by 3-(4,5-dimethylthiazol-2-yl)-2,5-diphenyl tetrazolium bromide assay

All the 72 Trichosporon isolates produced biofilm by MTT assay, out of which, $16(22.2 \%)$ were weak biofilm producers, $29(40.3 \%)$ were moderate biofilm producers, 27 (37.5\%) were strong biofilm producers. In this assay, the mean $\mathrm{A}_{450 / 620}$ (read/reference) value was $0.631(\mathrm{SD}+0.3)$ with a range of $0.197-1.42$ that corresponds to 7.2-fold difference between the highest and the lowest biofilm producer. Majority of the blood isolates and PCN isolates, i.e., $10 / 12$ and 5/7 were strong biofilm producers [Table 2]. The mean absorbance value for blood and PCN isolates was found to be high, i.e., 9.5 and 9.8, respectively [Figure 3]. Although isolates from particular sample sources (peritoneal fluid, blood, and PCN) were observed to be high biofilm producers, there was no much difference observed in biofilm production

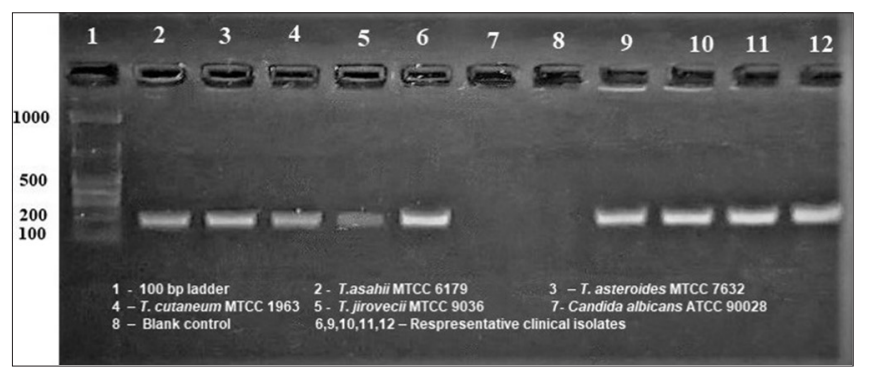

Figure 2: Trichosporon specific polymerase chain reaction

Table 1: Biochemical profile and growth characteristics of Trichosporon spp.

\begin{tabular}{|c|c|c|c|c|c|c|c|c|c|c|c|c|}
\hline \multirow[t]{2}{*}{ Number of isolates $(n=72)$} & \multicolumn{8}{|c|}{ Assimilation of } & \multicolumn{3}{|c|}{ Growth } & \multirow[t]{2}{*}{ Final identification } \\
\hline & Rha & Mel & Raff & Rib & Xyl & L-Arab & Galac & Ino & $0.1 \%$ & $37^{\circ} \mathrm{C}$ & App & \\
\hline 32 & + & - & - & - & - & + & - & - & + & + & - & T. asahii \\
\hline 17 & + & - & - & + & - & + & - & - & + & + & - & T. asahii \\
\hline 15 & + & - & - & - & + & + & - & - & + & + & - & T. asahii \\
\hline 5 & - & - & - & - & - & + & - & + & + & + & - & T. asteroides \\
\hline 2 & + & + & + & + & + & + & - & + & - & - & - & T. cutaneum \\
\hline 1 & + & + & + & + & + & + & + & + & + & + & - & T. mucoides \\
\hline
\end{tabular}

Rha $=$ Rhamnose, $\mathrm{Mel}=$ Melibiose, Raff $=$ Raffinose, Rib $=$ Ribose, $\mathrm{Xyl}=$ Xylose, $\mathrm{L}$-Arab $=\mathrm{L}$-arabinose, Galac $=$ Galactose, Ino $=$ Inositol, $0.1 \%=$ Growth on medium with $0.1 \%$ cycloheximide, $37^{\circ} \mathrm{C}=$ Growth at $37^{\circ} \mathrm{C}, \mathrm{App}=$ Appresoria, T. asahii $=$ Trichosporon asahii, $T$. asteroides $=$ Trichosporon asteroids, T. cutaneum $=$ Trichosporon cutaneum, T. mucoides $=$ Trichosporon mucoides, $+=$ Assimilated,$-=$ Not assimilated 
among phenotypically characterized species of the genus Trichosporon.

The OD values of the control strains used in our study are shown in Figure 4. There was a significant difference between the biofilm production by CV method and MTT assay for the reference strains [Table 3].

\section{Comparison of biofilm production}

The MTT assay detected more weak, moderate and strong biofilm producers than $\mathrm{CV}$ method. The isolates which were negative by $\mathrm{CV}$ method were either weak (53.3\%), moderate $(43.3 \%)$, or strong $(3.3 \%)$ biofilm producers by MTT assay [Table 4].

\section{Discussion}

Trichosporon species are emerging nosocomial pathogens, frequently associated with infections in indwelling medical devices. ${ }^{[18,19]}$ Their infective capacity depends on specific virulence factors, which gives them the ability to colonize mucosal or synthetic surface and invade host tissues by disrupting host-cell membranes. Hence, persistent and recurrent infections are a common occurrence in such cases. ${ }^{[20]}$ Furthermore, biofilm production renders them refractory to antimicrobial treatment, therefore high antimicrobial concentrations are required to inactivate such organisms growing in a biofilm.

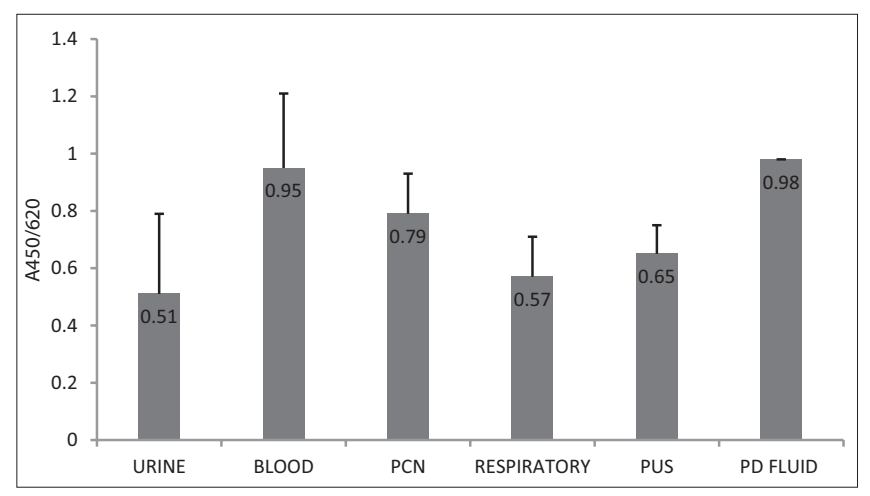

Figure 3: Mean OD values of different sample sources
Various methods have been employed for the detection of fungal biofilms. Newer techniques such as DNA extraction and quantification polymerase chain reaction is time-consuming and expensive. ${ }^{[21]}$ In this study, we compared two frequently described, different procedures for quantifying the biofilm formation. All the 72 clinical isolates of Trichosporon spp. were tested for biofilm production by test tube method with $\mathrm{CV}$ staining and MTT assay using 96-well microtiter plate.

The test tube method using CV staining identified $42 / 72(58.3 \%)$ of the isolates as biofilm producers, out of which 5 (6.9\%) were weak biofilm producers, $17(23.6 \%)$ were moderate biofilm producers, and $20(27.8 \%)$ were strong biofilm producers. CV is a reliable tool for determining bulk biofilm formation produced by fungal cells since it stains the metabolically active and inactive cells in mature biofilms. ${ }^{[22,23]}$

All the isolates tested in our study produced biofilm by MTT assay, in which $16(22.2 \%)$ were weak biofilm producers, $29(40.3 \%)$ were moderate biofilm producers, and $27(37.5 \%)$ were strong biofilm producers. This finding was similar to the study done by Wei sun et al., where all the isolates produced biofilm on polystyrene surface. ${ }^{[2]}$ This phenomenon has important clinical implications for therapy of biofilm-associated infection, which is difficult to treat and recurs easily. ${ }^{[25]}$

Biofilm production has been evaluated in laboratory settings using microtiter plates. ${ }^{[2]}$ This method is most

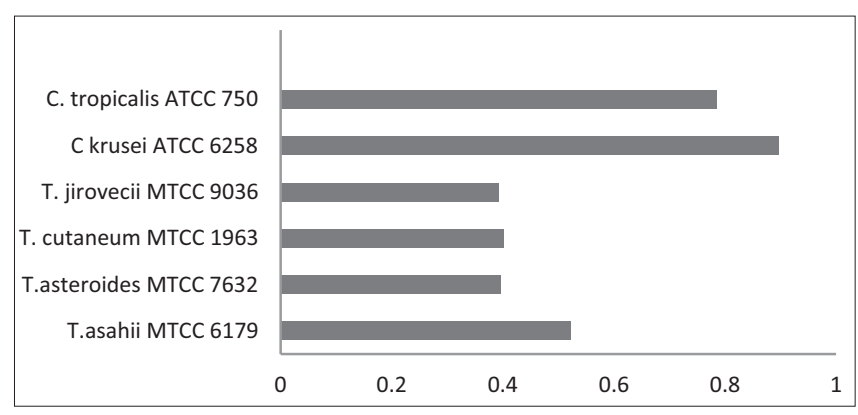

Figure 4: OD values of Control strains of Trichosporon spp. and Candida sp.

Table 2: Grading of biofilm production by crystal violet-tube method/3-(4, 5-dimethylthiazol-2-yl)-2,5-diphenyl tetrazolium bromide method

\begin{tabular}{lcccccccc}
\hline Sample source & \multicolumn{2}{c}{ Negative 0 } & \multicolumn{2}{c}{ Weak 1+ } & \multicolumn{2}{c}{ Moderate 2+ } & \multicolumn{2}{c}{ Strong 3+ } \\
\cline { 2 - 8 } & CV (\%) & MTT (\%) & CV (\%) & MTT (\%) & CV (\%) & MTT (\%) & CV (\%) & MTT (\%) \\
\hline Urine $(n=43)$ & $25(58.1)$ & 0 & $3(7)$ & $16(37.2)$ & $8(18.6)$ & $16(37.2)$ & $7(16.3)$ & $11(25.6)$ \\
PCN $(n=7)$ & 0 & 0 & 0 & 0 & $3(42.9)$ & $2(28.6)$ & $4(57.1)$ & $5(71.4)$ \\
Blood $(n=12)$ & $1(8.3)$ & 0 & $1(8.3)$ & 0 & $4(33.3)$ & $2(16.7)$ & $6(50)$ & $10(83.3)$ \\
Respiratory $(n=5)$ & $2(40)$ & 0 & $1(20)$ & 0 & $1(20)$ & $4(80)$ & $1(20)$ & $1(20)$ \\
Pus $(n=4)$ & $2(50)$ & 0 & 0 & 0 & $1(25)$ & $3(75)$ & $1(25)$ & $1(25)$ \\
PD fluid $(n=1)$ & 0 & 0 & 0 & 0 & 0 & 0 & $1(100)$ & $1(100)$ \\
Total & $30(41.7)$ & 0 & $5(6.9)$ & $16(22.2)$ & $17(23.6)$ & $27(37.5)$ & $20(27.8)$ & $29(40.3)$ \\
\hline
\end{tabular}

*Using Chi-square test we found a statistically significant association $(P=0.004)$, between sample source and biofilm production by MTT assay at $P<0.05$. CV $=$ Crystal violet, $\mathrm{PCN}=$ Percutaneous nephrostomy, PD = Peritoneal dialysis, MTT = 3-(4, 5-dimethylthiazol-2-yl)-2,5-diphenyl tetrazolium bromide 
Table 3: Biofilm quantification by crystal violet and 3-(4, 5-dimethylthiazol-2-yl)-2,5-diphenyl tetrazolium bromide assay for control strains

\begin{tabular}{lll}
\hline Control strains & Tube method-CV assay & MTT assay \\
\hline T. asahii MTCC 6179 & Negative & Moderate \\
T. asteroides MTCC 7632 & Negative & Moderate \\
T. cutaneum MTCC 1963 & Negative & Moderate \\
T. jirovecii MTCC 9036 & Negative & Moderate \\
C. krusei ATCC 6258 & Weak & Strong \\
C. tropicalis ATCC 750 & Moderate & Strong \\
\hline
\end{tabular}

T. asahii = Trichosporon asahii, T. asteroides = Trichosporon asteroids, T. cutaneum $=$ Trichosporon cutaneum, $T$. jirovecii $=$ Trichosporon jirovecii, C. krusei $=$ Candida krusei, $C$. tropicalis $=$ Candida tropicalis, CV = Crystal violet, MTT = 3-(4, 5-dimethylthiazol-2-yl)-2,5-diphenyl tetrazolium bromide

Table 4: Comparison of biofilm production by crystal violet-tube method and $3-(4$, 5-dimethylthiazol-2-yl)-2,5-diphenyl tetrazolium bromide assay

\begin{tabular}{llcccc}
\hline Method & Biofilm grading & \multicolumn{3}{c}{ MTT assay } & \multirow{2}{*}{$P^{*}$} \\
\cline { 3 - 5 } & & Weak (\%) Moderate & $\begin{array}{c}\text { Strong } \\
(\%)\end{array}$ & $(\%)$ \\
\hline Tube & Weak $(n=5)$ & 0 & $5(100)$ & 0 & 0.000 \\
method & Moderate $(n=17)$ & 0 & $9(52.9)$ & $8(47.1)$ & \\
& Strong $(n=20)$ & 0 & 0 & $20(100)$ & \\
& Negative $(n=30)$ & $16(53.3)$ & $13(43.3)$ & $1(3.3)$ & \\
& Total & $16(22.2)$ & $27(37.5)$ & $29(40.3)$ & \\
\hline
\end{tabular}

*Using Chi-square test we found a statistically highly significant difference between biofilm production by CV-tube method and MTT assay at $P<0.001$. CV = Crystal violet, MTT = 3-(4, 5-dimethylthiazol-2-yl)-2,5-diphenyl tetrazolium bromide

popular due to its versatility, simplicity, reproducibility, and efficiency. MTT-reduction assay shows excellent correlation between cellular density and metabolic activity, thus providing semiquantitative measurement of biofilm formation. ${ }^{[23,27]}$ This colorimetric assay has the additional benefit in contrast to other methods such as $\mathrm{CV}$ staining that, it correlates with cell viability which is particularly useful for measuring the effects of drugs on biofilm cells. MTT is reduced by mitochondrial dehydrogenases of metabolically active biofilm cells and is, therefore, the best approach to test the effect of drug exposure on the biofilm viability. ${ }^{[2,29]}$

Isolates from peritoneal fluid, blood, and PCN had high mean OD values in MTT assay, and majority of them (i.e., $1 / 1 ; 10 / 12 ; 5 / 7)$ were strong biofilm producers. In another study by Iturrieta-González et al., Trichosporon spp. were high biofilm producers in blood, urine, and skin samples. ${ }^{[30]}$ High adherence and biofilm formation may promote colonization and establishment of infection even in samples collected from superficial sites.

However, test tube method by CV staining when compared to MTT assay, could not identify weak and moderate biofilm producers efficiently. The detection percentage was high in MTT assay $(22.2 \%$ and $40.3 \%)$ when compared to CV assay $(6.9 \%$ and $23.6 \%)$. This finding is consistent with the observation made by Mathur et al. Test tube method with CV staining can be a good technique for biofilm quantification, but it has a high degree of subjective variability in reading and cannot accurately detect moderate-to-weak biofilm producers. ${ }^{[13]}$

\section{Conclusion}

MTT assay using microtiter plates detects more biofilm producers compared to test tube method by $\mathrm{CV}$ staining, in our study. This method has been widely used by researchers to study biofilm formation and quantification, making it more reliable and comparable among different laboratories, a necessary step toward the standardization of antifungal susceptibility testing of biofilms.

\section{Financial support and sponsorship Nil.}

\section{Conflicts of interest}

There are no conflicts of interest.

\section{References}

1. Donlan RM, Costerton JW. Biofilms: Survival mechanisms of clinically relevant microorganisms. Clin Microbiol Rev 2002;15:167-93.

2. Kolter R. Biofilms in lab and nature: A molecular geneticist's voyage to microbial ecology. Int Microbiol 2010;13:1-7.

3. Costerton JW, Cheng KJ, Geesey GG, Ladd TI, Nickel JC, Dasgupta $\mathrm{M}$, et al. Bacterial biofilms in nature and disease. Annu Rev Microbiol 1987;41:435-64.

4. Middelhoven WJ. Identification of clinically relevant Trichosporon species. Mycoses 2003;46:7-11.

5. Di Bonaventura G, Pompilio A, Picciani C, Iezzi M, D'Antonio D, Piccolomini R, et al. Biofilm formation by the emerging fungal pathogen Trichosporon asahii: Development, architecture, and antifungal resistance. Antimicrob Agents Chemother 2006;50:3269-76.

6. Kuhn DM, Ghannoum MA. Candida biofilms: Antifungal resistance and emerging therapeutic options. Curr Opin Investig Drugs 2004;5:186-97.

7. Mermel LA, Allon M, Bouza E, Craven DE, Flynn P, O'Grady NP, et al. Clinical practice guidelines for the diagnosis and management of intravascular catheter-related infection: 2009 update by the Infectious Diseases Society of America. Clin Infect Dis 2009;49:1-45.

8. Magalhães AR, Mondino SS, Silva Md, Nishikawa MM. Morphological and biochemical characterization of the aetiological agents of white piedra. Mem Inst Oswaldo Cruz 2008;103:786-90.

9. Vijayakumar R, Giri S, Kindo AJ. Molecular species identification of Candida from blood samples of Intensive Care Unit patients by polymerase chain reaction-restricted fragment length polymorphism. J Lab Physicians 2012;4:1-4.

10. Sugita T, Nishikawa A, Shinoda T. Rapid detection of species of the opportunistic yeast Trichosporon by PCR. J Clin Microbiol 1998;36:1458-60.

11. De Hoogs GS, Guarro J, Gene J, Figueras MJ. Atlas of clinical fungi, 
$2^{\text {nd }}$ ed. Guanabara, Rio de Janeiro, Brazil. Centraalbureauvoor Schimmelcultures Utrecht, The Netherlands, and Universitat Rovirai Virgili, Reus, Italy; 2000.

12. Christensen GD, Simpson WA, Bisno AL, Beachey EH. Adherence of slime-producing strains of Staphylococcus epidermidis to smooth surfaces. Infect Immun 1982;37:318-26.

13. Mathur T, Singhal S, Khan S, Upadhyay DJ, Fatma T, Rattan A. Detection of biofilm formation among the clinical isolates of staphylococci: An evaluation of three different screening methods. Indian J Med Microbiol 2006;24:25-9.

14. Jin Y, Samaranayake LP, Samaranayake Y, Yip HK. Biofilm formation of Candida albicans is variably affected by saliva and dietary sugars. Arch Oral Biol 2004;49:789-98.

15. Traba C, Liang JF. Susceptibility of Staphylococcus aureus biofilms to reactive discharge gases. Biofouling 2011;27:763-72.

16. Tsang PW, Bandara HM, Fong WP. Purpurin suppresses Candida albicans biofilm formation and hyphal development. PLoS One 2012;7:e50866.

17. Stepanović S, Vuković D, Hola V, Di Bonaventura G, Djukić S, Cirković I, et al. Quantification of biofilm in microtiter plates: Overview of testing conditions and practical recommendations for assessment of biofilm production by staphylococci. APMIS 2007;115:891-9.

18. Moretti-Branchini ML, Fukushima K, Schreiber AZ, Nishimura K, Papaiordanou PM, Trabasso P, et al. Trichosporon species infection in bone marrow transplanted patients. Diagn Microbiol Infect Dis 2001;39:161-4.

19. Pini G, Faggi E, Donato R, Fanci R. Isolation of Trichosporon in a hematology ward. Mycoses 2005;48:45-9.

20. Walsh TJ, Groll A, Hiemenz J, Fleming R, Roilides E, Anaissie E, et al. Infections due to emerging and uncommon medically important fungal pathogens. Clin Microbiol Infect 2004;10 Suppl 1:48-66.

21. Taff HT, Nett JE, Andes DR. Comparative analysis of Candida biofilm quantitation assays. Med Mycol 2012;50:214-8.

22. Ramage G, Vande Walle K, Wickes BL, López-Ribot JL.
Standardized method for in vitro antifungal susceptibility testing of Candida albicans biofilms. Antimicrob Agents Chemother 2001;45:2475-9.

23. Hawser SP, Norris H, Jessup CJ, Ghannoum MA. Comparison of a 2,3-bis(2-methoxy-4-nitro-5-sulfophenyl)-5-[(phenylamino) carbonyl]-2H-t etrazolium hydroxide (XTT) colorimetric method with the standardized National Committee for Clinical Laboratory Standards method of testing clinical yeast isolates for susceptibility to antifungal agents. J Clin Microbiol 1998;36:1450-2.

24. Sun W, Su J, Xu S, Yan D. Trichosporon asahii causing nosocomial urinary tract infections in intensive care unit patients: Genotypes, virulence factors and antifungal susceptibility testing. J Med Microbiol 2012;61:1750-7.

25. Shin JH, Kee SJ, Shin MG, Kim SH, Shin DH, Lee SK, et al. Biofilm production by isolates of candida species recovered from nonneutropenic patients: Comparison of bloodstream isolates with isolates from other sources. J Clin Microbiol 2002;40:1244-8.

26. Nett JE, Cain MT, Crawford K, Andes DR. Optimizing a candida biofilm microtiter plate model for measurement of antifungal susceptibility by tetrazolium salt assay. J Clin Microbiol 2011;49:1426-33.

27. Jin Y, Zhang T, Samaranayake YH, Fang HH, Yip HK, Samaranayake LP. The use of new probes and stains for improved assessment of cell viability and extracellular polymeric substances in Candida albicans biofilms. Mycopathologia 2005;159:353-60.

28. Bizerra FC, Nakamura CV, de Poersch C, Estivalet Svidzinski TI, Borsato Quesada RM, Goldenberg S, et al. Characteristics of biofilm formation by Candida tropicalis and antifungal resistance. FEMS Yeast Res 2008;8:442-50.

29. Jabra-Rizk MA, Falkler WA, Meiller TF. Fungal biofilms and drug resistance. Emerg Infect Dis 2004;10:14-9.

30. Iturrieta-González IA, Padovan AC, Bizerra FC, Hahn RC, Colombo AL. Multiple species of Trichosporon produce biofilms highly resistant to triazoles and amphotericin B. PLoS One 2014;9:e109553. 